ЗНАМЕНСКИЙ Дмитрий Юрьевич - кандидат политических наук, доцент кафедры государственного управления и политических технологий Института государственного управления и права Государственного университета управления (109542, Россия, г. Москва, Рязанский пр-кт, 99; belyferz@list.ru)

ГУСАРОВА Анжелика Николаевна - аспирант кафедры государственного управления и политических технологий Института государственного управления и права Государственного университета управления (109542, Россия, г. Москва, Рязанский пр-кт, 99)

\title{
К ВОПРОСУ ОБ ИНСТИТУЦИОНАЛЬНЫХ ОСНОВАХ ГОСУДАРСТВЕННОЙ ИННОВАЦИОННОЙ ПОЛИТИКИ В СОВРЕМЕННОЙ РОССИИ
}

Аннотация. В статье раскрываются проблемы формирования государственной инновационной политики и ее институциональных основ в современной России. С этой целью в статье дается обзор системы государственного управления инновационной деятельностью, проводится анализ программных документов политических партий, отражающих степень их участия в разработке инновационной политики государства, рассматривается роль бизнес-структур, НКО и т.д. в обозначенных процессах. По мнению авторов, институциональное обеспечение взаимодействия власти и общества должно найти отражение в концепции государственной инновационной политики.

Ключевые слова: государство, инновации, государственная инновационная политика, политические институты, политические партии, НКО

A ктуальность проблем государственной инновационной политики в современной России не вызывает сомнений. С одной стороны, данная проблематика практически постоянно стоит в политической повестке дня, составляет содержание выступлений лидеров государства, руководителей отраслевых органов власти, представителей гражданского общества. В то же время нельзя не отметить, что, по мнению многих отечественных и зарубежных ученых, за последние 25 лет современным органам власти так и не удалось воспользоваться конкурентными преимуществами, доставшимися от Советского Союза, и создать новые. В этой связи представляется справедливым мнение американского экономиста Дж. Стиглица, указывавшего, что переход к рыночной экономике в России... отрицательно сказался на благосостоянии российских граждан [Стиглиц 2003: 44].

Подтверждением сказанного служат данные официальной статистики. Так, реальные располагаемые денежные доходы (за вычетом обязательных платежей, скорректированные на индекс потребительских цен) в 2015 г. по сравнению с 2014 г. снизились на 4,0\%1. В 2016 г. данный показатель снизился на 5,9\%, причем в декабре 2016 г. по сравнению с соответствующим периодом предыдущего года - на 6,8\%2. Подобная тенденция сохраняется и в 2017 г.

Думается, что все изложенное актуализирует исследование проблем государственной инновационной политики, в т.ч. в части более тесного взаимодействия между властью и обществом в процессе разработки соответствующих приоритетов. В качестве методологической основы наиболее уместным в данном случае представляется системно-динамический подход, предполагающий ана-

\footnotetext{
${ }^{1}$ Официальный сайт Федеральной службы государственной статистики. 2015. Доступ: http://www.gks. ru/free_doc/doc_2015/social/osn-12-2015.pdf

2 официальный сайт Федеральной службы государственной статистики. 2016. Доступ: http://www.gks. ru/free_doc/doc_2016/social/osn-12-2016.pdf
} 
лиз как минимум трех измерений политики: пространственного, временно́го и технологического. Первое сопряжено с областью осуществления политики, а также с политическими институтами, задействованными в этом процессе. Второе предполагает выделение ряда этапов жизненного цикла политики, а именно последовательную смену стадий ее формирования, реализации, оценки ее эффективности. Третье означает ключевую роль технологий взаимодействия власти, бизнеса и общества в рассматриваемых процессах [Знаменский, 2014а: 104].

Конкретизируя содержание пространственного измерения государственной инновационной политики, следует отметить важное значение ее нормативноправовых и концептуальных, а также институциональных основ. Первые задают основные направления и методы реализации политики. Что касается вторых, то необходимо заострить внимание на том, какие институты заинтересованы в данном направлении политики и осуществляют разработку и непосредственное регулирование этого направления.

Характеризуя нормативно-правовые основы государственной инновационной политики, нельзя не отметить их фрагментарность, выражающуюся в большом количестве пробелов в правовом регулировании инновационной деятельности. Действительно, несмотря на признаваемую большинством экспертов объективную потребность, федеральный закон о государственной инновационной политике до сих пор не принят. Его отсутствие обусловливает разнонаправленность регионального законодательства в области инновационной политики, что существенным образом усложняет правовое регулирование данной сферы. В качестве наиболее успешных региональных практик в данной сфере можно считать опыт Московской обл., Татарстана и ряда других субъектов РФ.

Не меньшее значение имеют институциональные основы государственной инновационной политики. Именно политические институты задают ключевые параметры развития национальной инновационной системы в целом. Это заключается: 1) в определении формата участия государственных органов в ее развитии; 2) формировании нормативно-правовой базы инновационной деятельности; 3) построении системы отношений между субъектами инновационной политики.

В качестве основных институтов, вовлеченных в процесс формирования национальной инновационной системы, можно назвать государство, местное самоуправление, институты производства и распространения знаний, бизнес, институты рыночной инфраструктуры.

Так, государство выполняет, с одной стороны, роль регулятора системы общественных отношений в области инновационной деятельности, а с другой - осуществляет управление собственной государственной инновационной деятельностью. Конечный результат проводимой государственной политики выражается в виде определенного состояния бизнес-климата, набора макроэкономических условий, а также характера государственного администрирования, благоприятствующих активизации инновационной деятельности.

Бизнес-сообщество, участвующее в инновационном процессе, также представляется неоднородным. Условно можно выделить две группы, которые имеют принципиально разную целевую ориентацию, а следовательно выстраивают разную систему взаимодействий с органами государственной власти и местного самоуправления.

Первая группа - институты коммерциализации инновационных продуктов и услуг (венчурные, лизинговые организации, консалтинговые агентства и т.д.). Вторая группа - производственные компании, ключевые субъекты инновационной деятельности, связывающие воедино усилия всех участников инноваци- 
онной системы до той степени, когда на выходе получается готовый инновационный продукт с фиксированным финансовым результатом (малый и средний бизнес, транснациональные компании, а также научно-технические альянсы, свободные экономические зоны и др.).

В фокусе интересов институтов гражданского общества находятся вопросы уровня жизни и благосостояния населения, что достигается в т.ч. через развитие науки и внедрение инноваций в реальный сектор. В то же время нельзя не отметить неоднородность указанных институтов и разнонаправленность их целей и установок. В этой связи обращает на себя внимание возрастающая в современных условиях роль так называемого функционального представительства, которым обозначают всю совокупность взаимоотношений государства и групп интересов.

Детальный анализ институциональных основ государственной инновационной политики представляется целесообразным начинать с государства и системы органов государственной власти, участвующих в формировании и реализации данной политики.

Существенная роль президента РФ в процессе определения основных направлений внутренней и внешней политики обусловливает интерес к совещательным органам по вопросам науки и технологий, функционирующим при главе государства. В частности, следует обратить внимание на Совет по науке и образованию при Президенте РФ. Совет является совещательным органом при рассмотрении вопросов, связанных с развитием науки и образования, а также вырабатывает предложения для президента РФ по актуальным вопросам государственной политики в области научно-технического развития и образования. Так, в рамках заседания Совета проходило обсуждение проекта Стратегии научно-технологического развития Российской Федерации.

Непосредственное участие в формировании государственной инновационной политики принимает также Совет при Президенте РФ по модернизации экономики и инновационному развитию России. Данный совещательный орган координирует деятельность органов власти, экспертного сообщества и бизнес-сообщества в данной сфере, также определяет формы и методы государственного регулирования в сфере модернизации экономики и инновационного развития.

Одним из важных направлений деятельности Совета, на наш взгляд, является работа межведомственной рабочей группы по разработке и реализации Национальной технологической инициативы при президиуме Совета. Роль Совета при Президенте РФ по модернизации экономики и инновационному развитию России, по нашему мнению, в основном заключается в обсуждении хода реализации НТИ, а также в подготовке предложений по своевременному «приспособлению законодательства» к реализуемым инициативам.

Что касается законодательной ветви власти, то здесь речь должна идти главным образом о профильных комитетах палат Федерального собрания. Так, в структуре Совета Федерации необходимо обозначить комитет Совета Федерации по науке, образованию и культуре, к ведению которого относятся, помимо прочего, вопросы государственной политики в сфере научной, научно-технической и инновационной деятельности, а также правовой охраны результатов интеллектуальной деятельности. Согласно отчету об итогах работы комитета Совета Федерации по науке, образованию и культуре в 2016 г. ${ }^{1}$, принципиальным решением в сфере научной и научно-технической

\footnotetext{
${ }^{1}$ Сайт Комитета Совета Федерации по науке, образованию и культуре. 2017. Доступ: http://science. council.gov.ru/activity/plans/79096/
} 
политики Российской Федерации в 2016 г. было отнесение Стратегии научнотехнологического развития Российской Федерации к документам стратегического планирования. В 2017 г. комитет также участвовал в подготовке новой редакции федерального закона «О науке и государственной научно-технической политике».

В составе Государственной думы в рамках данного исследования следует обратить внимание на комитет по образованию и науке и комитет по экономической политике, промышленности, инновационному развитию и предпринимательству. Одним из важных принятых законов, по мнению авторов, является федеральный закон «Об инновационных научно-технологических центрах и о внесении изменений в отдельные законодательные акты Российской Федерации» ${ }^{1}$. Такие центры представляют собой совокупность организаций, ведущих научно-технологическую деятельность, действующих на определенной правительством территории. По своей сути они будут иметь особый юридический статус и режим осуществления деятельности, аналогичные особым экономическим зонам, а принципиальное отличие последних заключается в том, что они включают в себя развитие не только высокотехнологичных отраслей, но и обрабатывающих отраслей экономики, транспортной инфраструктуры. В то же время цель инновационных научно-технологических центров - осуществление научно-технологической деятельности, в т.ч. коммерциализация ее результатов.

Среди связанных с предметом настоящего исследования вопросов ведения комитета Госдумы по экономической политике, промышленности, инновационному развитию и предпринимательству следует отметить законодательное обеспечение организации и функционирования особых экономических зон, территорий опережающего развития и территориально-инновационных кластеров, инновационного развития и модернизации российской экономики, приоритетное развитие рынка промышленной, интеллектуальной собственности, развитие инновационных центров и др. ${ }^{2}$

Что же касается исполнительной ветви власти, то следует заметить, что в правительстве РФ в процессах формирования и реализации государственной инновационной политики участвуют департаменты Аппарата Правительства РФ, в т.ч. департамент науки, высоких технологий и образования. Стоит особо отметить значительное число совещательных и координационных органов при правительстве РФ. В целях формирования единой государственной инновационной политики данные структуры обеспечивают взаимодействие федеральных органов исполнительной власти, органов исполнительной власти субъектов федерации и иных организаций в целях реализации единой государственной политики в области научно-технической и инновационной политики.

Кроме того, участие в реализации государственной инновационной политики принимают следующие органы исполнительной власти.

1. Минобрнауки России, которое осуществляет выработку и реализацию государственной политики и правовое регулирование в сфере образования, научной, научно-технической и инновационной деятельности.

2. Ряд федеральных органов исполнительной власти, которые выступают в

\footnotetext{
1 Федеральный закон от 29 июля 2017 г. № 216-Ф3 «Об инновационных научно-технологических центрах и о внесении изменений в отдельные законодательные акты Российской Федерации». Доступ: https://duma.consultant.ru/documents/3719493 (проверено 18.05.2018).

2 Сайт Комитета Государственной Думы по экономической политике, промышленности, инновационному развитию и предпринимательству. 2017 Доступ: http://www.komitet2-7.km.duma.gov.ru/Voprosyvedeniya
} 
качестве соисполнителей в процессе формирования и реализации государственной инновационной политики, в т.ч.:

а) Минэкономразвития России (согласование НПА, регулирующих инновационную деятельность в РФ, участие в реализации проектов инновационного центра «Сколково»);

б) Минфин России (бюджетное обеспечение инновационной политики и аудит, участие в плане мероприятий по стимулированию инновационного развития России);

в) Минэнерго России (инновационное развитие отраслей ТЭК);

г) Федеральное агентство научных организаций (правовое регулирование, оказание услуг в сфере организации деятельности, осуществляемой подведомственными организациями, в т.ч. в области науки, образования, развитие инновационной деятельности научных организаций);

д) Федеральная служба по интеллектуальной собственности (правовая защита интересов государства в процессе экономического и гражданско-правового оборота научно-исследовательских результатов).

Думается, что на федеральном уровне с позиции как законодательной, так исполнительной ветвей власти предусмотрено немалое число структур, принимающих участие в формировании и реализации государственной инновационной политики. Вместе с тем возникает вопрос об эффективности этих структур власти в части решения проблем инновационной политики на федеральном уровне.

Из описанного выше напрашивается вывод: если на решение конкретной проблемы существует «политический заказ», решение таких проблем идет гораздо быстрее. Представляется, что в отношении государственной инновационной политики такого заказа в настоящее время нет либо он является несущественным.

Особое место во взаимодействии между властью и обществом занимают политические партии. Очевидно, что выстраивание государственной политики в любой сфере трудно представить без их участия.

Думается, в России наиболее активное участие в формировании государственной политики принимает партия власти, в то время как при фактически декларативном характере многопартийности ни парламентская, ни внесистемная оппозиция не оказывают существенного влияния на принятие политических решений.

Обширный материал в рассматриваемой области содержится в программных документах действующих думских партий. Так, в программе партии «Единая Россия» есть раздел, посвященный инновационному потенциалу и человеческому капиталу здравоохранения. Среди дальнейших действий, предлагаемых партией, также содержатся действия, направленные в основном на модернизацию в сфере здравоохранения. Но следует отметить, что по всему документу точечно всплывают лозунги, обращающие внимание электората на важность технологического развития страны ${ }^{1}$. Что касается реализации политических лозунгов, то здесь, помимо законотворческой деятельности партии, существуют партийные проекты, направленные на становление экономики инновационного типа.

КПРФ также обращает внимание на необходимость становления инновационной экономики, базирующейся не на частной, а на коллективной собственности, при этом наука должна являться непосредственной производительной силой общества. По мнению членов партии, научно-техниче-

\footnotetext{
1 Официальный сайт партии «Единая Россия». 2017. Доступ: http://er.ru/
} 
ский прогресс ведет к коренному качественному и структурному обновлению рабочего класса города и деревни, являющегося основной социальной опорой партии.

Программа ЛДПР также содержит в себе отдельные точечные предложения, связанные с формированием инновационной политики государства в части поддержки малого бизнеса в науке, формирования в обществе культа труда инженера, конструктора, ученого с одновременным созданием высокотехнологичных предприятий и использованием высококвалифицированных кадров.

В программном документе политической партии «Справедливая Россия» также имеется особый раздел, посвященный развитию российской науки, основанному на полноценном государственном финансировании фундаментальной науки и прикладных исследований в наиболее перспективных отраслях с целью устранения эксплуатации интеллекта как дешевой рабочей силы и перехода к продаже интеллектуального продукта ${ }^{1}$.

Одним из важных, на наш взгляд, предложений партии «Справедливая Россия», не упомянутых в программах вышеперечисленных партий, является принятие крупных управленческих решений по вопросам развития науки и результатов научных разработок с учетом мнения научного и педагогического сообщества страны. Также предусмотрена поддержка инновационных предприятий в виде налоговых льгот, финансирование вузовской науки, увеличение в 3-5 раз объема государственных научных стипендий и грантов и т.д. По примеру западных стран и Китая партия предлагает создать централизованный орган исполнительной власти - Министерство науки и высоких технологий, ответственный за инновационное развитие страны, за реализацию инновационной политики.

Учитывая изложенное, можно сделать вывод, что ни одна парламентская партия не отрицает актуальность адекватной инновационной политики государства и потребность в ней, и все они являются активными участниками ее формирования с точки зрения теории. С точки зрения практики ведущее место занимает «Единая Россия», которая в настоящее время имеет реальные возможности для реализации своих партийных предложений путем осуществления конкретных проектов и оказывает существенное стратегическое влияние на определение вектора инновационной политики России. Вместе с тем необходимо принимать во внимание, что чем больше «Единая Россия» находится у центра принятия решений, тем больше к ней вопросов и требований со стороны общественности и тем активнее в стране формируется потребность в оппозиции, которая стимулирует спрос на иные политические институты, способные воздействовать на общую обстановку и политический курс.

Вместе с тем нельзя не отметить, что кризис партийного представительства, ощущаемый в большинстве демократических государств, актуализирует потребность в развитии механизмов функционального представительства общественных интересов, которое должно основываться на непартийных общественнополитических институтах. Основной их целью является не завоевание политической власти, а оказание на нее влияния, в т.ч. путем участия в обсуждении законодательных инициатив. Так, в разработке и обсуждении нового закона «О научной, научно-технической и инновационной деятельности в Российской Федерации», помимо Минобрнауки России и иных заинтересованных федеральных органов исполнительной власти, активное участие принимали науч-

1 Программа партии «Справедливая Россия». - Официальный сайт партии «Справедливая Россия». Доступ: http://31.44.80.183/files/pf59/075833.pdf (проверено 12.03.2018). 
ные учреждения, бизнес-структуры, госкомпании - городской научно-технический совет г. Обнинска, Российская академия наук, АО «Рособоронэкспорт» и т.Д.

Что касается НКО, то они могут выявлять инновационные потребности общества. Стоит согласиться с мнением Е.В. Гончаровой и Д.Е. Кондратицкого относительно того, что некоммерческий сектор эффективно оказывает услуги обществу, он способен оперативно реагировать на нужды различных социальнодемографических групп, на новые социальные вызовы и проблемы [Гончарова, Кондратицкий 2017: 558]. В рамках данного исследования следует обратить внимание на такие формы НКО, как: а) центры публичной политики; б) государственные и общественные академии наук; в) государственные и общественные научные фонды; г) общественные советы и иные консультативные структуры при органах власти и научно-исследовательских структурах; д) союзы молодых ученых [Знаменский 2014б: 2].

Вместе с тем следует отметить дистанцированность российской власти от НКО в силу ряда причин. Так, многие политологи отмечают факт влияния таких организаций на дестабилизацию ситуации в странах, где в нулевых годах прошли так называемые цветные революции. В указанных случаях НКО выступили реальной силой для смены политической элиты, что в итоге объясняет появление в России нового законодательства об НКО, которое многие эксперты оценили как репрессивное [Сунгуров 2009: 502]. Ужесточение законодательства, сокращение финансирования повлияли не только на принудительный уход с политической арены многих НКО, но и на их самоликвидацию (например, Фонд «Либеральная миссия», поддерживавший российскую науку более 20 лет).

В этой связи важно не упускать из виду существенный риск невостребованности потенциала добросовестных и политически не ангажированных НКО [Гимазова, Омельченко 2015: 283], которые могут стать полноценными и эффективными партнерами государства в решении многих социальных проблем, в т.ч. в сфере инновационной политики.

В контексте настоящего исследования стоит обратить внимание и на такую форму НКО, как общественные академии наук, созданные коллективами ученых на добровольной основе в 1990-х гг. и участвующие в координации научной деятельности. Однако следует согласиться с рядом исследователей [Глазьев 2013: 57; Знаменский 2015: 35], которые подчеркивают, что потенциал общественных академий наук недостаточно реализован, в первую очередь ввиду того, что их кадровый резерв зачастую не соответствует академическому уровню.

Более результативно проявляют себя государственные и негосударственные научные фонды. В числе первых ведущее место занимают РФФИ и РНФ. Важная роль РФФИ выражается в том, что в рамках предлагаемой поддержки научных исследований большое внимание уделяется системе взаимосвязи между участниками инновационного процесса. Для реализации этой задачи фонд заключил соглашения с федеральными органами исполнительной власти, государственными корпорациями, координаторами технологических платформ, бизнес-структурами и другими институтами развития в области инновационной деятельности. Не обходятся без поддержки регионы и зарубежные партнеры, сотрудничество с которыми осуществляется в форме совместных конкурсов, двусторонних и многосторонних соглашений. К негосударственным научным фондам следует отнести организации, учреждаемые, как правило, крупными корпорациями, заинтересованными в развитии конкретной сферы экономики, или же научными организациями, такими как Фонд инфраструктурных и обра- 
зовательных программ (Группа РОСНАНО), Международный центр фундаментальной физики в Москве, Фонд поддержки образования и науки (Алферовский фонд) и т.д.

Также заслуживает внимания такой общественно-политический институт, как Российский союз молодых ученых (РоСМУ). Предполагается, что этот союз влияет на расширение взаимодействия между молодыми учеными с целью обмена новыми знаниями и последующего развития творческого потенциала, реализуемого в конкретных достижениях. Однако следует обратить внимание на недостаточно высокую активность данной организации в рассматриваемой области.

На федеральном уровне среди общественных организаций, способных существенно влиять на становление инновационной экономики, следует выделить Общественную палату РФ. Среди комиссий, входящих в структуру палаты, всегда были комиссии, так или иначе принимавшие участие в формировании государственной инновационной политики. В период 2006-2008 гг. существовала комиссия Общественной палаты по инновациям, высокотехнологичным научным и инженерным проектам, деятельность которой была направлена на инновационное развитие экономики на базе российских высоких технологий, безопасную эксплуатацию зданий, сооружений и производств, популяризацию достижений культуры, науки и техники, освоение и развитие на базе научного потенциала территорий Урала, Сибири, Дальнего Востока и Севера России. В 2008-2010 гг. вопросами инновационной экономики занималась комиссия Общественной палаты по образованию и науке, в 2010-2014 гг. комиссия по науке и инновациям, в 2014-2017 гг. - комиссия по развитию науки и образования. В настоящее время в рамках работы шестого состава палаты (2017-2020 гг.) предусмотрена комиссия по развитию образования и науки. При этом среди действующих основных направлений деятельности Общественной палаты развитие инноваций отсутствует.

Подводя итоги проведенного исследования, нельзя не согласиться с тем, что государство всегда было и остается основным субъектом инновационной политики. Доминирующий подход к формированию государственной научнотехнической политики Российской Федерации можно условно назвать государственно-административным, т.е. приоритеты государственной политики определяются Министерством образования и науки при некотором участии гражданского общества.

Многие отечественные политологи справедливо полагают, что нынешняя стабилизация российской политической системы отнюдь не способствует развитию институтов отечественной публичной политики. Думается, что развитие институционального обеспечения взаимодействия власти, общества и бизнеса должно стать одним из основополагающих направлений будущей концепции государственной инновационной политики.

\section{Список литературы}

Гимазова Ю.В., Омельченко Н.А. 2015. К вопросу о разграничении политического и социального в деятельности российских негосударственных некоммерческих организаций. - Вестник университета (Государственный университет управления). № 13. С. 278-284.

Глазьев С.Ю. 2013. База для рывка. - Эксперт. № 9. С. 57-58.

Гончарова Е.В., Кондрацкий Д.Е. 2017. Инновационный потенциал некоммерческих организаций в России. - Научно-методический электронный журнал «Кониелт». Т. 2. С. 556-560.

Знаменский Д.Ю. 2014а. Системно-динамический подход к исследованию 
процесса формирования и реализации государственной политики. - Теория и практика общественного развития. № 12. С. 104-106.

Знаменский Д.Ю. 2014б. Деятельность социально ориентированных НКО в области науки и технологий: системно-динамический подход. - Социодинамика. № 9. С. 1-14.

Знаменский Д.Ю. 2015. Государственная научно-техническая политика на современном этапе. - Власть. № 8. С. 35-36.

Стиглиц Дж. 2003. Глобализация: тревожные тенденции. М.: Мысль. 81 с.

Сунгуров А.Ю. 2009. Модели взаимодействия структур гражданского общества и органов власти: российский опыт. - Модернизация экономики и глобализация. В 3 кн. (отв. ред. Е.Г. Ясин). М.: ИД ГУ-ВШЭ. Кн. 1. С. 500-508.

ZNAMENSKY Dmitriy Yur'evich, Cand.Sci. (Pol.Sci.), Associate Professor of the Chair of Public Administration and Political Technologies, Institute of Public Administration and Law, State University of Management (99 Ryazansky Ave, Moscow, Russia, 109542; belyferz@list.ru)

GUSAROVA Anzhelika Nikolaevna, postgraduate student of the Chair of Public Administration and Political Technologies, Institute of Public Administration and Law, State University of Management (99 Ryazansky Ave, Moscow, Russia, 109542)

\section{ON THE QUESTION OF THE INSTITUTIONAL FOUNDATIONS OF PUBLIC INNOVATION POLICY IN MODERN RUSSIA}

Abstract. The subject of this study is the institutional basis of public innovation policy in modern Russia. The relevance of this topic is due to both the attention to it from the political leadership, and the pressing needs of the Russian economy. By the authors' opinion, a full analysis of this policy area should be based on consideration of its institutional foundations from the point of view of interaction of political institutions both in the process of forming the respective priorities of the innovation policy and in the process of its implementation.

The place of partial and functional representation of public interests in the existing system of innovative activity management is indicated. The novelty of the study is a detailed analysis of the role of government bodies at various levels, institutions of civil society, political parties, and business structures in the formation and implementation of public innovation policy.

Keywords: state, innovations, public innovations policy, political institutes, political parties, non-government organizations 